\title{
Análisis de supervivencia de cáncer de mama temprano
}

- Pedro Luis Ramos Guette, María Athenas Ramos Escalante, Diana Silva, Mario González, Mauricio García Oncológica Oncocare (Bogotá, D.C.)

Introducción: el cáncer de mama temprano se asocia con un buen pronóstico. El propósito del estudio es establecer la supervivencia global y libre de enfermedad en pacientes con cáncer de mama temprano.

Materiales y métodos: es un estudio analítico con cohorte retrospectivo realizado durante el período del $1^{\circ}$ enero de 2003 hasta el 30 de mayo de 2016. Se incluyeron todas las pacientes mayores de 18 años con cáncer de mama estadios I y II. Se construyeron curvas de supervivencia con el método de Kaplan-Meier, se compararon con el método de rangos logarítmicos y se realizó un análisis de regresión de rangos proporcionales por Cox.

Resultados: se identificó un total de 272 pacientes con un promedio de edad de 56 años, el 61,7\% tenían ganglios negativos y el $67 \%$ eran posmenopáusicas. Así mismo, el $79 \%$ tenían receptor de estrógenos positivos y el $24 \%$, HER2 positivo. Se presentaron recaídas en un $12,87 \%$ y la mortalidad fue del $11,03 \%$. No se alcanza la mediana de supervivencia global, con una mediana de seguimiento de 90 meses. La supervivencia global y libre de enfermedad no se asocia con el estado ganglionar, estado de los receptores hormonales, HER2, ni las respuestas patológicas completas.

Conclusiones: los pacientes con cáncer de mama temprano tienen un muy buen pronóstico, con excelente supervivencia global y libre de enfermedad. 